\title{
Entre bibliófilos e bibliodetetives: dinâmicas de objeto e valor, questões de informação
}

\author{
Kelly Castelo Branco da Silva Melo \\ http://orcid.org/0000-0003-4505-0688 \\ Leila Beatriz Ribeiro ${ }^{I I}$ \\ http://orcid.org/0000-0003-2462-6553
}

IUniversidade Federal do Estado do Rio de Janeiro, RJ, Brasil.

Doutora e Mestre em Memória Social.

Professora Assistente do Departamento de Biblioteconomia.

${ }^{I I}$ Universidade Federal do Estado do Rio de Janeiro, RJ, Brasil.

Doutora em Ciência da Informação pela Universidade Federal do Rio de Janeiro.

Professora Associada II.

http://dx.doi.org/10.1590/1981-5344/3586

O presente artigo pressupõe que a literatura policial, como gênero literário e modo de registro e expressão de experiências (ficcionais), possibilita a análise/interpretação e representação de determinadas práticas colecionistas e de quadros de referências sóciohistóricos. Como um desdobramento de estudos sobre bibliofilia, o artigo toma como campo empírico cinco romances policiais escritos pelo norte-americano John Dunning, e,por meio da leitura analítica desses livros, propõe teórica e metodologicamente identificar e observar as questões informacionais que permeiam/emergemdas dinâmicas de valor encontradas nas tramas. 0 fluxo dos livros enquanto mercadorias e objetos de coleção, e o seu transitar para dentro e para fora da situação mercadológica, resultam da convergência complexa de aspectos sociais, temporais e culturais. Sendo assim, o 
artigo se volta para os processos de (des)valorização de livros, visando neles elucidar o que é possível depreender do universo bibliófilo, e o que, nesse universo ficcional, constitui e representa práticas informacionais utilizadas por/em um universo colecionista não ficcional.

Palavras-chave: Bibliofilia; Romance Policial; Valor; Informação.

This article is based on the premise that crime fiction, as a literary genre and also as means of recording and expressing (fictional) experiences, allows the analysis/interpretation and representation of certain collecting practices and of socio-historical references. As a productof studies onbibliophilia, the article takes five police novels written by the American John Dunning as empirical field, and, through the analytical reading of these books, proposes, theoretically and methodologically, to identify and observe the informational issues that permeate/emerge from value dynamics found in the plots. The flow of books as goods and objects of collection, and their passage into and out of the market situation, result from the complex convergence of social, temporal, and cultural aspects. Thus, the article turns to the processes of (de)valuing of books, in order to elucidate what can be deduced about the bibliophile universe, and what, in this fictional universe, constitutes and represents informational practices used by/in a non-fictionalcollecting universe.

Keywords: Bibliophilia; Crime fiction; Value; Information.

Recebido em 04.07.2018 Aceito em 03.08.2020

\section{Introdução}


Desde o surgimento dos primeiros artefatos, os objetos acompanharam o homem como prolongamentos de suas ações no mundo. Ao fazê-lo, promoveram mudanças não apenas para fora - para o/no ambiente -, como também para dentro - atuando no homem e o transformando.Em todas as sociedades e culturas as coisas têm seu lugar e se mostram participantes ativosdas/nas dinâmicas sociais, inclusive as de troca informacional - e não apenas como suporte.No âmbito da sociedade de consumo, objetos se encontram atrelados à concepção de mercadoria, como se essa lhes fosse uma característica inata. Nossa perspectiva, no entanto, é appaduraiana, ou seja, a de que quando falamos em 'mercadoria', referimo-nosa um estado na/da vida social das coisas, umafase em sua existência.Nesse sentido, trata-se de um 'estar mercadoria', mais do que um 'ser mercadoria':apenas o período durante o qual a trocabilidade passa a ser o aspecto fundamental do objeto, ou, ainda, "seu traço social [mais] relevante" (APPADURAI, 2008, p. 27). Tanto o fluxo das mercadorias, como o seu transitar para dentro e para fora da situação mercadológica, resultam da convergência complexa de aspectos sociais, temporais e culturais (APPADURAI, 2008) e se encontram profundamente atrelados à questão do valor/valorização, o que faz das dinâmicas valorativas uma rica fonte de informação para melhor compreensão da(s) sociedade(s).

O presente artigo é um desdobramento de uma dissertação de mestrado sobre bibliofilia (colecionismo de livros), defendida em $2015^{1}$, inserida em um projeto de pesquisa ${ }^{2}$ que entende a coleção como narrativa e espaço de construção de memórias. Narrativa porque, resgatando a relação entre colecionar e narrar (MARSHALL, 2005), propomos que colecionar é narrar (informar) com objetos; e espaço de construção de memórias porque elas "trazem em si valores atribuídos por seus colecionadores" que "podem ser estendidos e atrelados às construções coletivas retomando a lembranças de todo um grupo social, e refletindo os valores das sociedades" (RIBEIRO, 2010, p. 6-7), possibilitando, por meio de seus elementos, a construção, preservação e circulação de informação ( $e$, através da informação, a memória) e o comunicar de algo sobre os colecionadores, funcionando como um meio

\footnotetext{
${ }^{1}$ MELO, Kelly Castelo Branco da Silva. Bibliófilos e bibliodetetives: personagens de patrimônio e memória. 2015. 175 f. Dissertação (Mestrado em Memória Social) Programa de Pós-graduação em Memória Social, Universidade Federal do Estado do Rio de Janeiro, Rio de Janeiro, 2015.

2 RIBEIRO, Leila Beatriz. Mais do que posso contar: coleções, imagens e narrativas. In: PROGRAMA DE PÓS GRADUAÇÃO EM MEMÓRIA SOCIAL. Processo seletivo discente: cursos mestrado e doutorado: edital n. 12/2015, 2014. Disponível em: http://www.memoriasocial.pro.br/pdf/edital.pdf. Acesso em: 28 set. 2014.
} 
pelo qual o colecionador se transmite adiante. A dissertaçãoem questão se desenvolveu a partir de uma série policial, escrita pelo norte-americano John Dunning - composta por cinco títulos, a saber: Edições perigosas (2007), Impressões e provas (1996), A promessa do livreiro (2006), Assinaturas e assassinatos (2008), e O último caso da colecionadora de livros (2009) -, e tomou-a como campo,percebendo-a como uma coleção: a coleção do bibliófilo livreiro, John Dunning (autor), que representa sua vivência/experiência de bibliofilia utilizando como recurso a ficção policial. Aqui, prosseguimos com a exploração dessa coleção, escolhendo como corte temático as questões informacionais que permeiam asdinâmicas de valor/valorização nessa série-coleção ${ }^{3}$.

A partir do prisma do colecionismo, voltamo-nos paraoscilações, na trajetória das coisas, que depreendemos dos processos de (des)valorização de livros encontradas na série: de mercadoria para ex-mercadoria "coisas retiradas, quer temporária ou permanentemente, do estado de mercadoria e postas num outro estado" (APPADUARAI, 2008, p. 31) -, de semióforo - objeto extraordinário, colecionável(POMIAN, 1984) - para objeto comum, ordinário, utilitário e vice-versa. O que localiza esses objetos em um ou outro extremo do pêndulo, e o que faz com que eles transitem entre esses polos, são as perguntas que nortearam nosso raciocínio.

As ferramentas metodológicase direcionamentospara a análise que realizamos são o resultado de leituras no âmbito da Memória Social, dos estudos sobre Objetos e Cultura Material, e sobre Bibliofilia/Colecionismo. Uma vez tendo-as realizado, ocupamo-nos da leitura, releitura e observação analítica dos romances - ou seja, da exploração do nosso campo empírico -, mapeando no texto todos os livros (uma vez que a série explora o colecionismo de livros, esses são os objetos de/em protagonismo nela)postos em destaque por Dunning no decorrer das tramas, esuas respectivas descrições. Nesse processo, percebemos queesses objetos (em geral, objetos de coleção) são descritos em termos de valor: de troca, de uso, afetivo, etc., mas principalmente de troca, já que o personagem principal da série é um ex-policial bibliófilo e livreiro norte-americano, e que todas as histórias se desenvolvem no âmbito do circuito das trocas e atividades econômicas do mercado de livros antigos e raros. Para o presente trabalho, partindo do pressuposto que por meio das dinâmicas de valorização é possível compreender toda uma série de elementos sócio-históricos e culturais, e que a questão do valor é central na temática das coleções, escolhemos alguns desses livros destacados(os

${ }^{3}$ Outros aspectos e questões foram abordados no artigo "Para cada universo colecionista, suas fontes: dinâmicas informacionais nas tramas de Clifford Janeway", publicado na revista Em Questão. 
que julgamos mais significativos)para, por meio dos valores que thes são atribuídos e demais aspectos qualificadores, fazer ver o que é possível compreender/decupar do universo das práticas bibliófilas (colecionistas) e seus quadros de referência.

\section{Ficção como fonte: literatura policial, memória, informação}

A escrita auxilia na construção da memória cultural e coletiva de uma sociedade, na medida em que, em todas as suas manifestações e junto a outros meios, como tecnologia de mídia, amplia o espectro espaço-temporal das formas de compartilhamento de experiências(ERLL, 2010). As formas de escrita ficcional - também como meios comunicacionais de recordações/lembranças - têm por característica o poder de influência e moldagem tanto da imaginação coletiva de passado/presente/futuro, como da ideia/percepção de realidade (ERLL, 2010). Como campo de manifestações artísticas, a literatura compõe um conjunto vasto de transfigurações do real -recriação da realidadepor meio do artista (COUTINHO, 1978). Como a realidade é algo alterado e transformado constantemente, na literatura é possível observar essas mudanças serem retransmitidas "através da língua para as formas, que são os gêneros" (COUTINHO, 1978, p. 10). Criados por necessidades próprias de um determinado campo comunicacional, os gêneros são tipos relativamente estáveis de enunciado (BAHKTIN, 2011). Sendo assim, são modos específicos de aplicação da linguagem, que seguem normas sociais discursivas características de cada circunstância/campo, em consonância com o contexto no qual acontecem os atos de fala (BAKHTIN, 2011). Ao entendermos que os "gêneros discursivos são práticas sócio-históricas" (MARCUSCHI, 2002, p. [19]), ou seja, que são "enunciados sóciohistoricamente situados" (COSTA; ORRICO, 2009, p. [2]), percebemos que neles é possível encontrar, em evidência, aspectos constitutivos de suas sociedades de origem (TODOROV, 1980).

O romance policial é um gênero literário que tem como presença marcanteo crime e a investigação. Embora não haja consenso quanto aos seus precursores, há unanimidade no reconhecimento de que esse gênero é inaugurado com a obra Os assassinatos da Rua Morgue, de Edgar Allan Poe, publicado em 1841 no periódico Graham's Magazine (DIAS, 1998; FREITAS, 2007). Alguns elementos característicos do contexto temporal e social no qual o romance policial se consolida, que possibilitam sua emergência, são: o processo acelerado de urbanização (cidades como ambientes propícios às atividades criminosas) vinculado à industrialização; a disseminação da imprensa; o crescimento do público consumidor de jornais; a influência do positivismo;e o surgimento da figura do policial/detetive (DIAS, 1998; FREITAS, 2007). Intencionando ser o mais 
objetiva e verossímil possível, a narrativa policial tem, como foco principal, o processo de resolução do mistério/crime, sendo este o que dá partida no desenrolar das tramas. Há, portanto, certa "ênfase positivista no raciocínio e na lógica" (FREITAS, 2007, p. 2), que é o que diferencia o romance policial dos demais tipos (DIAS, 1998). "A familiaridade crescente com o repertório científico e o tipo de raciocínio que este demandava foram decisivos para os desdobramentos desse [...] gênero" (ALMEIDA, 2012, p. 107), que se fortalece e ganha contornos mais definidos com a presença do imaginário científico (ALMEIDA 2012). Se os gêneros refletemmudançasocorridas na vida social (BAHKTIN, 2011), na literatura policial, encontramos, dentre as transformações sociais por ela refletidas e dela constituintes,fundamentalmente, a tomada da ciência como tema central do cenário cultural (ALMEIDA, 2012). "Os procedimentos investigativos que constituíram o coração de diversas narrativas policiais [...] emulavam os procedimentos científicos [...] e contribuíram, a seu modo, para ajudar a popularizar certa ideia de ciência diante do grande público" (ALMEIDA, 2012, p. 116). Howard Becker (2009) reforça nossa forma de investigar empiricamente tanto a literatura como fonte, como as fontes utilizadas pelos personagens literários (e os personagens como fontes), que conduzem à reflexão sobre as diferentes formas de representaçãodo social.

\section{Narrador-colecionador na (não) ficção}

Nosso campoé constituído por uma série policial que tem por personagem principal um detetive bibliófilo ('bibliodetetive') chamado Clifford Janeway. Quando estesurgiuna vida de seu criador, Dunning trabalhava já há oito anoscomo dono de uma livraria especializada em livros usados e raros (DUNNING, [2014]) - exatamente o cenário onde as tramas dos romances se desenvolvem. Ao falar sobre Janeway, Dunning afirma que este é uma mistura das atitudes e características de alguns policiais que ele conheceu durante a época em que trabalhou no Denver Post, cobrindo a sessão policial do jornal (DUNNING, 2000, [2014]), e das suas próprias. O entrelaçamento (proximidade/similaridade) das histórias de vida de Dunning e Janeway é evidente. Assim como o escritor, seu personagem mora em Denver (EUA) e é livreiro; ambos têm uma livraria no lado leste da cidade (pelo menos até 1994, quando Dunning fechou sua livraria física para continuar com uma loja online) (DUNNNG, 2000, [2014]). Os espaços onde as histórias de Janeway acontecem são lugares onde as histórias/experiências de Dunning se passaram: Denver - que está, mesmo que de forma distante, em todos os romances da série -, Charleston - cidade onde Dunning cresceu e que compõe uma parte central em $A$ promessa do livreiro -, o circuito dos hipódromos e estrebarias em Idaho e na Califórnia - onde Dunning trabalhou, em sua 
juventude, para criadores e treinadores de cavalos, assim como Janeway em $O$ último caso da colecionadora de livros -, o circuito das feiras de livros - frequentado por Dunning, como livreiro, e que é retomado por Janeway em Assinaturas e assassinatos. Nesse livro, aliás, um dos personagens (um livreiro e amigo de Janeway chamado Jim Pepper) é "amigo e companheiro livreiro" de John Dunning fora das páginas (DUNNING, 2000, tradução nossa). Esse espelhamento criação/criador confere ao imaginário da série um firme ancoramento no real, reforçadopelo fato de estarmos tratando de romances policias, que têm, por característica preponderante, a verossimilhança (ALMEIDA, 2012; DIAS, 1998). Ele também traz um tom autobiográfico para o universo da literatura policial, um aroma de 'guia de bibliofilia', similar ao que encontramos em textos de bibliófilos escritos sobre colecionismo.

\section{Falando em livros, logo objetos}

O livro é um objeto importante mnemônica e informacionalmente falando. Ainda que não sejam considerados seus conteúdos,sua materialidade já contém vasta gama de conhecimento adquirido, acumulado, transformado e aplicado à sua tecnologia. Cada uma das transformaçõespor ele sofridas ao longo dos séculos pode ser entendida comouma janela a abrir-se para outras épocas, e, por conseguinte, para as necessidades e dinâmicas de suas sociedades de origem. Afinal, como não se confecciona um instrumento sem uma demanda prévia a qual ele venha atender, na história dessa confecção há também uma história social.

Assim como a jornada das coleções, a jornada dos objetos é trans histórica e trans-cultural. Os utensílios mais antigos de que se tem conhecimento datam de cerca três milhões de anos e consolidam o princípio da história dos artefatos (POMIAN, 1984). É nesse período que o homem começa a transformar materiais encontrados na natureza em ferramentas que atuam como prolongamentos de suas ações e realizam a mediação entre ele e o mundo (MOLES, 1981), possibilitando ao ser humano passar do papel de condicionado,ao de condicionador do ambiente (DOHMANN, 2013).Forja-se então uma parceira nunca mais desfeita, mas constantemente transformada, na medida em que o homem, de fabricante de instrumentos,torna-se, cada vez mais, um consumidor de objetos. Nesse sentido, a saga das coisas é uma jornada hierarquicamente ascendente, tendo em vista que os objetos passam a ocupar um espaço cada vez mais significativo em nossas vidas (MOLES, 1981; CHOAY, 2011), extrapolando a esfera da utilidade, para ocupar também a do simbólico.

Na categorização da hierarquia das coisas,presente tanto em Moles (1972; 1981), quanto em Pomian (1984), os objetos utilitários são 
localizados nos níveis mais baixos, enquanto os objetos mais simbólicos, em oposição, nos níveis superiores. Tal hierarquização parece reproduzir, no universo objetal, a polarização conceitual presente no pensamento ocidental, que coloca de um lado (nos níveis inferiores da hierarquia) as coisas mercantilizadas, e do outro, em oposição, as pessoas: representantes do universo de individualização e singularização (KOPYTOFF, 2008). É como se o processo de singularização (ascensão na hierarquia) implicasse, portanto, desmercantilização, inutilização (no sentido de afastamento do âmbito utilitário), o que aproximaria as coisas das pessoas, ou ainda, faria desses objetos mais simbólicos (semióforos) as 'pessoas' do mundo das coisas. Os objetos são hoje "mediador[es] universa[is]", elementos "revelador[es] da sociedade na progressiva desnaturalização desta", são recursos que possibilitam a construção não só do ambiente cotidiano, como também do eu, e que formam "sistema[s] de comunicação social, carregado[s] de valores como nunca no passado" (MOLES, 1981, p. 8), o que faz deles mediadores essenciais do corpo social (MOLES, 1981).

\section{Coleção: uma relação sujeito/objeto}

Rubens Borba de Moraes, na abertura de $\mathrm{O}$ bibliófilo aprendiz (2005), afirma que a pergunta 'por que se coleciona?' deve ser feitaaos psicanalistas, pois "só eles sabem quais os motivos inconfessáveis e escabrosos que levam um burguês pacato e morigerado a praticar atos perfeitamente simples e morais" (MORAES, 2005, p. 19). Note-se a conexão da figura do colecionador com a figura do burguês, concepção derivada do fato de as práticas colecionistas terem se intensificado com a emergência da classe burguesa e a produção em massa; e da história do colecionismo ter sido forjada junto com a noção de sujeito no Renascimento, atrelada às relações entre "poder, dinheiro e a possibilidade de colecionar" (OLIVEIRA; SIEGMANN; COELHO, 2005, p. 113). De fato, as razões colecionistas podem ser tão variadas quanto são as particularidades de cada colecionador - ou, como diz Janeway, "as idiossincrasias do animal humano" (DUNNING, 2009, p. 215) - estando invariavelmente atreladas a aspectos subjetivos, como o gosto, que acabam por determinar os tipos de coleção. Para alguns, um porque pode nem mesmo existir conscientemente, ou pode ser algo à la Isadora Duncan: se soubessem dizer, não precisariam colecionar, afinal, ainda que

\footnotetext{
${ }^{4}$ Possível referência a Freud - que era colecionador: "Durante 40 anos, Freud comprou uma obra por semana. Ele colocava as preferidas na escrivaninha e as acariciava" (CLAUDIO, 2010, p. [1]) - e ao fato de sua prática clínica ter se realizado, em sua maioria, com indivíduos da classe burguesa vienense.
} 
a coleção se faça discurso aos outros, ela é sempre, primeiramente, um discurso para si (BAUDRILLARD, 2012).

Embora os critérios de escolha colecionistas estejam, com frequência, atrelados à subjetividade, eles não são unicamente subjetivos. Da mesma forma que a comumente atribuída banalidade da coleção opera como um véu, escondendo uma série de processos e construções não banais, essa suposta subjetividade de escolha também encobre o papel daquilo que Bauman chamou de 'destino': um dos elementos que dão forma à vida humana: todas as coisas sobre as quais não se tem nenhuma influência, aquilo que estabelece a gama de opções possíveis dentro da realidade e do momento de cada um de nós (2011). Escolha é a palavra-chave do processo colecionista, uma palavra que implica ao mesmo tempo, o processo de seleção e o de valorização (PEARCE, 1992) e que faz convergir o individual e o coletivo. É no processo de escolha que habita a negociação do colecionador entre as normas sociais, os significados e valores previamente estabelecidos das coisas, e suas possibilidades de acumulação - e aqui, o termo 'acumulação' usado não no sentido de 'amontoar' (no tocante à mania, como o bibliômano que acumula livros indiscriminadamente), mas no de "associar", "aliar", juntar" (LUFT, 2011, p. 34) - para a construção de um sentido próprio (e que é só dele). Eis uma concepção fundamental no que diz respeito ao colecionar: construção de sentido. Comoo sujeito modernoé aquele que se vê responsável pela construção da própria identidade e por conferir sentido à própria vida (BAUMAN, 2011), em uma sociedade para a qual a acumulação de objetos é considerada uma forma de constituição subjetiva (OLIVEIRA; SIEGMANN; COELHO, 2005), o colecionismo e a sociedade ocidental capitalista se encontram cada vez mais coligados, com o primeiro se tornando uma ferramenta importante "na reconstrução subjetiva do indivíduo", uma vez que "a pergunta 'quem sou?' acaba sendo também respondida pelos referenciais atrelados às posses e propriedades do sujeito" (OLIVEIRA; SIEGMANN; COELHO, 2005, p. 113). No entanto, não se pode afirmar que acoleção seja um privilégio exclusivo da modernidade nem do mundo capitalista ocidental - muito embora possamos falar do colecionismo, prática socialmente instituída do colecionar,ou, como coloca Susan Pearce, do "colecionar como atividade autoconsciente $^{5 \prime \prime}$ (2013, p. 4, tradução nossa), como um fenômeno moderno.

\section{No colecionar, três aspectos}

${ }^{5}$ Do original em inglês: "collecting itself as a self-conscious activity". 
Prática, poética e política (practice, poetics and politics) são os três aspectos do colecionar apontados por Pearce (2013) que servem como parâmetro para os seus estudos. Segundo ela, prática diz respeito a que tipos de significados são dados socialmente aos objetos e às coleções; poética, a como os indivíduos se utilizam dessas construções para dar a seus objetos e coleções um significado próprio; e política trata de como o colecionismo une os dois aspectos anteriores para mostrar por que e como diferentes valores são atribuídos aos objetos e qual a sua importância.

Esses três aspectos se encontram representados com bastante evidência na série de Janeway, cuja trama é construídanas diversas situações mercantis e processos de valorização que os livros ocupam em diferentes momentos, para diferentes personagens. Eles estão representados, aliás, antes mesmo da série policial começar, no prefácio escrito por Dunning que abre a Kindle ${ }^{6}$ edition (2000), onde ele discute as mudanças no universo colecionista de livros acarretadas pela internet, e as novas dinâmicas de atribuição de valor, tão distintas daquelas em vigência no tempo em que as aventuras de Janeway se passam (década de 1980, início da década de 1990). "Esse longo preâmbulo", ele diz, "parece necessário porque Cliff Janeway, o herói da história que você está prestes a ler, é uma criatura desse outro tempo, essa era divisora de águas quando o frenesi dos preços ainda não havia atingido seu pico lamentoso ${ }^{7 "}$ (DUNNING, 2000). Na verdade, os tempos ao redor de Janeway já estão mudando e, nas histórias, ele se mostra como um dos resistentes; um dos que não querem que a aura se perca. "Um dos que colecionam livros por todos os motivos certos", e que, embora sejam "capitalista[s] o suficiente para aproveitar pechinchas, o preço raramente é sua motivação principal"8 (DUNNING, 2000).

Dunning explica essa guinada no ramo livreiro e colecionista utilizando como exemplo o caso de seu próprio livro, o Edições Perigosas (2007). Quando os 25 exemplares que ele havia encomendado para sua livraria venderam da noite para o dia, ele, como, livreiro do ramo de livros usados e raros, se viu incapaz de conseguir outros. Ele argumenta que isso se deu devido às novas práticas no ramo, impostas pelos novos tempos: livreiros comprando livros novos em grandes quantidadese os estocando, em uma aposta de que valorizem. "A internet virou o ramo de

\footnotetext{
${ }^{6}$ Leitor e programa de livros digitais da Amazon.

7 Do original em inglês: "This long preamble seems necessary because Cliff Janeway, the hero of the little brew your're about to read, is a creature of that other time, that watershed era when the feeding frenzy had not yet reached its wailing peak".

${ }^{8}$ Do original em inglês: "Janeway [...] collects books for all the right reasons [...]. He's enough of a capitalist to pick up bargains, but price is seldom his main motivation".
} 
cabeça pra baixo" ${ }^{\prime \prime}$, ele diz (2000). Dunning afirma que, antes de 1992, a mentalidade vigente era a de que um livro precisava estar no mercado há pelo menos algum tempo antes de adquirir algum tipo de valor. Depois de 1992, o ramo foi tomado pelo "fenômeno dos hipermodernos": livros cujas primeiras edições são procuradas e vendidas a preços astronômicos enquanto ainda nem saíram do mercado de livros novos. Sobre esse novo tipo de mentalidade ele diz: "gente que sabe o preço de tudo e o valor de nada ${ }^{10 "}$ (2000), que nos romances, parece estar representada pelos livros de Stephen King; livros que segundo Janeway "não fazem sentido, mas [...] impressionam pela capacidade de galgar as listas de mais vendidos, e no mundo de hoje é o que conta" (DUNNING, 2007, p. 52, grifo nosso). E continua: "o problema hoje em dia [...] é que o show biz passa com frequência por talento [...]. Cheguei à conclusão de que as pessoas que compram tais livros, não se importam nem um pouco com os livros" (DUNNING, 2007, p. 52).

As questões que remetem à prática, poética e política de Pearce povoam todos os cinco livros de Janeway/Dunning: o que tem valor? 0 que não tem? Por que? E, acima de tudo, para quem? São questões fundamentais.

De maneira geral, as coleções são paradoxos: mesmo retirados do circuito das mercadorias, os objetos que as constituem são considerados valiosos - e talvez, justamente por isso, se entendermos que "chamamos de valiosos aqueles objetos que opõem resistência a nosso desejo de possuí-los" (APPADURAI, 2008, p. 15, grifo nosso) -, e, mesmo destituídos de utilidade - ou libertos, como coloca Benjamin (2006) -, mantêm valor de troca, ou seja, têm valor de troca sem terem valor de uso (POMIAN, 1984) - "só um idiota leria uma primeira edição" (DUNNING, 2007, p. 18); "enquanto isso, se eu quiser ler aquele Steinbeck, posso comprar um exemplar barato e não ter que me preocupar se vou derramar café nele" (DUNNING, 2009, p. 75). Esse valor de troca pode ser conferido por inúmeros fatores, uma vez que emerge e opera em um domínio que não é "nem totalmente subjetivo, nem exatamente objetivo" (APPADURAI, 2008, p. 15). Um deles é o fato dos objetos de coleção, por serem semióforos, se encontrarem no mais alto nível hierárquico das coisas e sua posse, portanto, conferir prestígio, status, como se adquirir tal objeto, principalmente dentro de uma lógica burguesa, correspondesse, de certa forma, a ascender na hierarquia social.

\footnotetext{
9 Do original em inglês: "Internet has turned the trade on its head".

${ }^{10}$ Do original em inglês: "People who know the price of everything and the value of nothing".
} 
Tal reunião de semióforos, porém, não se dá de maneira indiscriminada. O ato de colecionar é sempre um ato de escolha e as questões que permeiam essa escolha não se esgotam em noções como o gosto e o interesse pessoais ou a busca por prazer estético. É certo que tais noções são importantes, mas elas são insuficientes para explicar o todo desse processo que faz convergir a complexidade do individual em negociação com o coletivo, conforme discutimos anteriormente. Faz-se necessário atentar para o fato de "o gosto se dirigir para certos objetos e não para outros, de se interessar por isto e não por aquilo" (POMIAN, 1984, p. 75). Afinal, se os semióforos realizam o intercâmbio entre o visível e o invisível, é a sociedade que delimita a fronteira entre essas duas dimensões, e esses limites refletem aquilo que é ou não significante para determinada sociedade, e quais objetos são por ela privilegiados (POMIAN, 1984).

Além da qualidade de semióforos, muitas vezes os objetos de coleção detêm características que os tornam únicos, senão raros, e, portanto, dentro de uma lógica de oferta e demanda, ainda mais valiosos - opõe ainda mais resistência e dificuldade à posse (APPADURAI, 2008) e desejados. No entanto, o valor de troca - seja ele atribuído ao objeto pelo status conferido por sua posse, ou por sua raridade, ou ambos - é um valor social, "depende do domínio cultural e social" (BAUDRILLARD, 2012, p. 98) e diz respeito a uma relação que parte do indivíduo para o exterior e não para o interior. Porém, a trocabilidade não é o único elemento a ser considerado na dinâmica de valorização entre coleção e colecionador. Como "não somos nós que nos transportamos para dentro" das coisas, mas "elas é que adentram nossas vidas" (BENJAMIN, 2006, p. [240]), a possível relação entre o valor da coleção e um provável status social ou entesouramento por ela proporcionado passa a ficar em segundo plano, na medida em que o colecionador se torna um "verdadeiro colecionador", que reconhece a singularidade absoluta dos objetos de sua coleção, não com base em critérios externos, mas no fato de serem possuídos por ele e permitirem neles se reconhecer. A valorizaçãoentão, inclina-se mais para a esfera do significado, do afeto, e vai se constituir das associações, das sensações, das lembranças - "não pensam no valor em termos de dinheiro [...] vivem num mundo diferente" (DUNNING, 2007, p. 335).

Ora, a história de sua "valorização" [dos objetos] é a história de qualquer coisa, porque une magicamente os relatos da vida psíquica mais individual ao movimento projetivo do sincretismo simbólico. 0 valor é o dizer do objeto devolvido como um espelho ao indivíduo e à coletividade (JEUDY, 1990, p. 65). 
Retomemos: "o valor é o dizer do objeto devolvido como um espelho ao indivíduo e à coletividade", ou seja, por mais que a escolha e a subjetividade do colecionador sejam elementos importantes a guiar suas escolhas, como dissemos anteriormente, elas não são inteiramente livres. Elas estão inseridas nos sistemas de valores das sociedades no bojo das quais colecionador e coleção são criados, e sempre remetem a esses sistemas, seja por repetição/propagação/aceitação, seja por transgressão/oposição. O "colecionador autêntico", como colocado por Walter Benjamin (1995), se afasta dos aspectos mercadológicos envolvidos no ato de colecionar e põe em destaque esse outro tipo de valor: aquele relacionado principalmente à afetividade.Segundo o autor, objetos de coleçãoinspiram "uma relação muito misteriosa com a propriedade" (1995, p. 228) na qual a função de serem utilizados é suprimida pela de serem possuídose a posse é empreendimento de totalização abstrata que afasta do mundo da dimensão prática, do objeto funcional, e que faz com que o objeto, tome um estatuto estritamente subjetivo: o de objeto de coleção (BAUDRILLARD, 2012). Na coleção, a posse é amorosa (BAUDRILLARD, 2012), inspiradora de devoção, que leva o colecionador a enxergar/sentir seus objetos "como palco, como o cenário do seu destino" (BENJAMIN, 1995, p. 228), e lançar sobre eles um olhar que enxerga para além da materialidade e do presente, que vê em cada objeto seu passado, sua vida pregressa, e que faz de cada um deles uma "enciclopédia mágica" (BENJAMIN, 2006, p. [241]).

É compreensível, portanto, que muitos colecionadores não se desfaçam de suas coleções, muito embora valiosas (valor de troca), nem frente a dificuldades financeiras. Para o colecionador, a coleção é mais que um mero conjunto de objetos: é paixão, um espaço de apego, de forma que a natureza do objeto em si ou a extensão de sua trocabilidade se torna irrelevante. Seu valor não mais é aquele que se projeta para fora, para a sociedade, mas um que se projeta e se instala no subjetivo, um território onde o objeto é retirado do mundo das mercadorias comuns - da situação mercantil - e passa a compor o espaço do sagrado (PEARCE, 2013; POMIAN, 1984), assumindo o papel de "ex-mercadoria" (APPADURAI, 2008, p. 31) e semióforo. Eis o ponto onde "o ser se instala no capitalismo, mas o subverte; rompe sua lógica ao produzir o inusitado" (OLIVEIRA; SIEGMANN; COELHO, 2005, p. 114). No entanto, na lógica do 'capital do conhecimento', principalmente aqueles que estão sendo transmitidos virtualmente. Ainda que "para ser vendido como mercadoria e aproveitado como capital, o conhecimento dev[a] se transformar em propriedade privada e tornar-se escasso" (GORZ, 2005, p.10). É o próprio autor que vai argumentar sobre a dificuldade de determinar onde começa e de que forma termina esse tipo de trabalho. O 'trabalho imaterial' de Dunning, representado e discutido abaixo, pode ainda ser problematizado 
dentro da lógica clássica marxista ou teremos de incluí-lo também, por exemplo, no paradigma da sociedade do conhecimento ${ }^{11}$

\section{Valor em questão}

Já dissemos antes que o processo de valorização - atrelado ao de seleção, uma vez que aquilo que se escolhe para compor a coleção tem algum valor para o colecionador - faz convergir as esferas do individual e do coletivo. Se a coleção permite produção de sentido é porque ela também obedece ou confronta uma lógica externa. No caso da série de Dunning e do universo colecionista, essa lógica é a de mercado - que comporta ainda atividades cognitivas: "O 'capitalismo cognitivo' é a crise do capitalismo em seu sentido mais estrito" (GORZ, 2005, p.37, grifos do autor). Se o valor não é algo inerente, mas se dá nas relações, essa categoria, mais do que tratar de uma característica específica dos objetos (livros) nas narrativas, quer mostrar a oscilação desses entre dois polos: do excepcional ao mundano, do "objeto de arte" ao objeto funcional, do livro-objeto ao objeto-livro (MOLES, 1981), de mercadoria (GORZ, 2005; POMIAN, 1984) à ex-mercadoria (APPADURAI, 2008); e do que motiva essas transições.

Segundo Moles (1981), os objetos de coleção podem ser avaliados em dois grupos: domésticos (objetos comuns: lápis, bibelô, etc.) e extradomésticos (objetos de arte). Em que grupo estariam os livros colecionados? Certamente há livros que podem ser categorizados objetos domésticos, mas os de uma coleção bibliófila tendem ao segundo grupo. Os tipos de coleção seguem de acordo: as de objetos comuns, aparentemente 'sem valor' - já que o valor que o colecionador atribui à sua coleção nem sempre está relacionado à sua trocabilidade -, e aquelas a que Moles chama "conjunto/rico", formadas por objetos com status de objetos dearte. $\mathrm{Na}$ "coleção bibliófila [...] o livro é antes de tudo um objeto, e a biblioteca, uma coleção de objetos caracterizados por traços relativos ao conteúdo mais que ao continente, formando um ciclo, o do objeto de arte, seja por sua forma externa, seja por sua forma interna" (MOLES, 1981, p. 141). No conjunto, sempre haverá um traço comum, a característica intersecional que concede coerência aos diferentes livros como partes desse todo: o critério de escolha.Critério esse que nem sempre é óbvio. O colecionador tem um propósito em mente (PEARCE, 1992) -que é o que o difere de um acumulador; a linha limítrofe entre

\footnotetext{
${ }^{11}$ É interessante ainda acompanhar a discussão de Gorz (2005) sobre questões que são debatidas na área de patrimônio cultural e ciência da informação: o 'saber fazer', as 'riquezas natura is' e a 'privatização' e o controle do direito e do acesso informacional para usufruto de determinados bens.
} 
bibliófilo (colecionador) e bibliômano (acumulador): aquele para quem ter livros torna-se mais importante do que quais livros ter -, porém:

Como e por que objetos chegam às coleções e talvez as deixem é bastante complexo e tem a ver com a interação sutil entre costumes sociais, idiossincrasias individuais e o brilho de significado que os objetos emitem por si só [...]. Nossas posses colecionadas estão próximas aos nossos corações e, assim como nossos corações, elas se mantêm, em última análise, misteriosas ${ }^{12}$ (PEARCE, 1992, p. 27).

Dito isso, podemos afirmar que os limites que dão forma à coleção de um bibliófilo são inúmeros: há os que colecionam livros de tipografias específicas, há os que colecionam por autor, por tema, por período histórico ou geográfico, aqueles que, como Janeway, primam pelas primeiras edições... Tão variadas são as opções- seja apenas uma, ou a combinação de várias - quanto as preferências e possibilidades de seus colecionadores. Há também marcas que tornam o objeto mais desejável, aquilo que o torna único e, se único, mais valioso:

Simmel sugere que os objetos não são difíceis de se adquirir porque são valiosos, "mas chamamos de valiosos aqueles objetos que opõem resistência a nosso desejo de possuí-los" [1978, p. 67]. O que Simmeldenomina, em particular, objetos econômicos existe no espaço entre o desejo puro e fruição imediata, com alguma distância entre eles e a pessoa que os deseja. Tal distância pode ser ultrapassada, o que ocorre por meio da troca econômica, na qual se determina reciprocamente o valor dos objetos. Ou seja, o desejo de alguém por um objeto é satisfeito pelo sacrifício de outro objeto, que é o foco do desejo de outrem. Tal troca de sacrifícios é o que constitui a vida econômica(APPADURAI, 2008, p. 16, grifo nosso).

Apesar de haver certo tom de crítica em falas de Janeway e de Dunning no tocante a livreiros e colecionadores que têm por principal

\footnotetext{
${ }^{12}$ Do original em inglês: "How and why objects arrive in our collections, and perhaps leave them again is very complex and has to do with the subtle interaction of social custom, individual quirk, and the glow of meaning which shines out of the object itself [...]. Our collected possessions lie close to our hearts and, like our hearts they remain, in the last analysis, mysterious".
} 
motivação o dinheiro, este é uma parte importante desse universo, visto que os livros são mercadorias e o olhar a partir do qual são vistos, na série, é mercadológico, devido ao fato de Janeway (e Dunning) ser livreiro.Os livros mencionados individualmente nos romancessão representativos disso. Todos eles estão inseridos e nos são apresentados dentro de uma dinâmica de mercado que segue a seguinte lógica: oferta e procura - e, com a 'capitalização' da produção do conhecimento, que vem, desde o final do século XIX, com a industrialização do "trabalho de pesquisa na indústria química na Bayer" (GORZ, 2005, p. 35).EmEdições perigosas (2007), quando Janeway fala sobre sua coleção, ele diz:

Meu apartamento parecia uma sucursal da biblioteca pública de Denver. As estantes até o teto ocupavam as paredes de todos os aposentos [...]. Não há exceção: são todos, primeiras edições. E, quando as pessoas tentam zombar de mim, adoro lembrar que minha cópia em perfeito estado de Lady in thelake, de Raymond Chandler, vale no mínimo mil dólares hoje (DUNNING, 2007, p. 19).

'Quanto vale e por quê?'são perguntas fundamentais nos percursos pelas histórias, principalmente atreladas às questões de transmissibilidade, uma vez que, em todos os romances, há um colecionador morto e uma coleção valiosa cujo destino interessa aos herdeiros; seja por questões afetivas, seja por questões econômicas. Oferta e demanda são os imperativos: "faz parte do modo de vida norteamericano", diz Janeway. "Se você possui algo que eu desejo, o preço será o máximo que puder pagar. Se tenho o único exemplar conhecido, prepare-se para vender sua casa, principalmente se houver mais gente interessada" (DUNNING, 1996, p. 28). Tallógica é observável no quadro a seguir, onde apresentamos alguns dos livros singularizados por Dunning ao longo da série ${ }^{13}$. Outras informações além do preço foram acrescentadas no campo do valor, nos casos em que determinadas falas de personagens foram tomadas por nós como relevantes para ilustrar as flutuações nas dinâmicas de valorização e os elementos que levam um livro a transitar, em ambos os sentidos, pelo caminho entre as situações livro-objeto e objeto-livro.

\footnotetext{
13 Em nossa pesquisa, fizemos esse mapeamento e construção tabular para todos os livros singularizados em todos romances da série. Entretanto, para este artigo, selecionamos apenas alguns.
} 


\section{Livro-objeto/objeto-livro}

\begin{tabular}{|c|c|c|c|}
\hline Títul o & Autor + conteúdo & Critério de excepcionali dade & Valor de troca \\
\hline $\begin{array}{l}\text { Mr. President } \\
(2007, \text { p. } 10)\end{array}$ & $\begin{array}{l}\text { Harry S. Truman; } \\
\text { William Hillman } \\
\text { "História do governo } \\
\text { Truman" (p. 10). }\end{array}$ & $\begin{array}{l}\text { “Autografado por Truman }[\ldots] \text { onde } \\
\text { também havia um texto manuscrito } \\
\text { pelo próprio Truman ocupando uma } \\
\text { página inteira" (p. 10). }\end{array}$ & US\$800 \\
\hline $\begin{array}{l}\text { The Magus } \\
\text { (2007, p. 10) }\end{array}$ & $\begin{array}{l}\text { John Fowles } \\
\text { "A estranha e } \\
\text { irresistível narrativa } \\
\text { mágica de John Fowles" } \\
\text { (p. 10). }\end{array}$ & $\begin{array}{l}\text { "Primeira edição britânica, com capa } \\
\text { impecável" (p. 10). }\end{array}$ & US\$300 \\
\hline $\begin{array}{l}\text { Tamerlane } \\
(2007, \text { p. } 48)\end{array}$ & Edgard Allan Poe & $\begin{array}{l}\text { "O primeiro livro de Edgard Allan } \\
\text { Poe" (p. 48). } \\
\text { "Não há ex emplares disponíveis" (p. } \\
48) . \\
\text { Somente cinquenta cópias produzidas } \\
\text { na primeira edição. }\end{array}$ & US\$250,000 \\
\hline $\begin{array}{l}\text { Firestarter } \\
(2007, \text { p. } 53)\end{array}$ & Stephen King & $\begin{array}{l}\text { "Edição limitadíssima e autografada" } \\
\text { (p.53). }\end{array}$ & $\mathrm{US} \$ 3,000$ \\
\hline $\begin{array}{l}\text { "Um } \\
\text { poem inha” } \\
(2007, \text { p. } 78)\end{array}$ & William Faulkner & $\begin{array}{l}\text { “Edição original de 1932, capa em } \\
\text { papel” (p. 78). }\end{array}$ & $\begin{array}{l}\text { Sem valor. } \\
\text { “Valeria U } \$ 250 \text { se alguém não tivesse } \\
\text { devolvido o jantar na primeira página” (p. 78). }\end{array}$ \\
\hline $\begin{array}{l}\text { "O primeiro } \\
\text { livro de Robert } \\
\text { Frost" } \\
(2007, \text { p. } 78)\end{array}$ & Robert Frost & Autografado & $\begin{array}{l}\text { Sem valor por ter sido "rabiscado por uma } \\
\text { criança" (p. 78, grifo nosso) }\end{array}$ \\
\hline $\begin{array}{l}\text { "Um Steinbeck } \\
\text { antigo" } \\
(2007, \text { p. } 78)\end{array}$ & John Steinbeck & "Em perfeito estado" & $\begin{array}{l}\text { Considerado sem valor devido à "página } \\
\text { inicial arrancada" (p. 78) }\end{array}$ \\
\hline $\begin{array}{l}\text { Moby Dick } \\
\text { (2007, p. 202) }\end{array}$ & Herman Melville & $\begin{array}{l}\text { "cópia }[\ldots . .] \text { que pertencera a } \\
\text { Hawthorne, com dedicatória comovida } \\
\text { de Melville, profusamente anotada }\end{array}$ & Não mencionado. \\
\hline
\end{tabular}




\begin{tabular}{|c|c|c|c|}
\hline & & $\begin{array}{l}\text { com a caligrafia de Hawthorne" (p. } \\
\text { 202). Quando a vê, Janeway diz: "ouvi } \\
\text { um suspiro profundo encher a sala. Em } \\
\text { seguida me dei conta de que era minha } \\
\text { própria voz" (p. 202). }\end{array}$ & \\
\hline $\begin{array}{l}\text { Smoky } \\
(1996, \text { p. 115) }\end{array}$ & Will James & $\begin{array}{l}\text { "O exemplar mais perfeito de Smoky } \\
\text { que eu já vira. Material de Will James, } \\
\text { autografado, começava a rarear, e } \\
\text { James não só assinara o livro como } \\
\text { também fizera um esboço original na } \\
\text { folha de rosto [...]. Talvez o melhor } \\
\text { exemplar existente no mundo" (p. } \\
\text { 115). }\end{array}$ & $\begin{array}{l}\text { US\$800 } \\
\text { “oumais” (p. 115). }\end{array}$ \\
\hline $\begin{array}{l}\text { The speeches of } \\
\text { Adlai Stevenson } \\
(2008, \text { p. } 68)\end{array}$ & Adlai E. Stevenson & $\begin{array}{l}\text { "Na página de rosto havia uma } \\
\text { pequena assinat ura, uma caligrafia que } \\
\text { eu conhecia muito bem. 'John } \\
\text { Steinbeck', eu disse [...]. 'Stevenson } \\
\text { não importa: a assinat ura dele étão } \\
\text { comum quanto poeira e tem o mesmo } \\
\text { valor. O nome de Steinbeck em um } \\
\text { pedaço de papel de parede vale } \\
\text { trezentos dólares" (p. 69-70). }\end{array}$ & US\$300 \\
\hline $\begin{array}{l}\text { Laura } \\
(2008, \text { p. 220) }\end{array}$ & Vera Caspary & $\begin{array}{l}\text { "Um exemplar imaculado [...]. Era } \\
\text { impossível encontrar o livro, em } \\
\text { qualquer lugar, por qualquer preço. Era } \\
\text { um livro tão raro que ninguém naquela } \\
\text { multidão jamais havia visto um } \\
\text { exemplar" (p. 220). }\end{array}$ & $\begin{array}{l}\text { Passou de mão de livreiro para mão de } \\
\text { livreiro, ainda dentro da Feira dos Livreiros } \\
\text { de Burbank (p. } 217) \text {, mudando de valor, } \\
\text { porque ninguém tinha exat a ideia de quanto } \\
\text { valia. Vendido por US } \$ 600 \text { para um livreiro } \\
\text { que o vendeu por US } \$ 1,500 \text {; que o passou } \\
\text { adiante por US } \$ 3,000 \text { a um livreiro que } \\
\text { vendeu para um outro por US\$6,000. "E o } \\
\text { livro foi vendido pela quarta vez, sem nunca } \\
\text { chegar ao estande que finalmente ficaria com } \\
\text { ele" (p. } 221) \text {. }\end{array}$ \\
\hline
\end{tabular}

Fonte: produção das autoras.

Nas dinâmicas de valorização e atribuição de preço podemos observar as particularidades do mercado livreiro - que correspondem ou atendem às particularidades desse tipo de colecionismo - e também acessar idiossincrasias individuais, a presença do sensualis mo, o fetiche, a empolgação/excitação - "ai meu coração" (DUNNING, 2009, p. 44) -, os pequenos elementos a dar margem às flutuações - uma mancha em uma edição original que reduz seu valor drasticamente, ou uma assinatura em uma edição barata que aumenta seu valor de forma igualmente drástica e comparativamente, as mutações sofridas pela sociedade, postas em destaque pelas notas de abertura de Dunning, tanto na edição brasileira de Edições perigosas (2007) - "negociantes de livros antigos, antes de discutir os preços mencionados, devem se lembrar que a história se passa em 1986. O valor de alguns exemplares subiu drasticamente nos últimos cinco anos" (2007, p. 7) - quanto no prefácio mais elaborado, da edição para Kindle, onde ele discute o fenômeno dos hipermodernos e, indiretamente, colecionadores e livreiros "autênticos" e "não autênticos". 
Não temos nesse quadro 'simplesmente' elementos descritivos e consubstanciados no valor de troca. Os critérios de excepcionalidade apontados por Dunning dão um 'veredicto' de um conhecedor da lógica de mercadoria, portanto de um especialista que 'autentica' um objeto-livro a partir do "'valor intrínseco' [que] se situa essencialmente fora da economia. Os valores intrínsecos - vitais no sentido de Max Scheler (força, agilidade, saúde, coragem), estéticos ou éticos -, não são nem comparáveis, nem permutáveis, nem intercambiáveis" (GORZ, 2005, p.55, grifo do autor).

Também, nesse quadro, a posição appaduraiana sobre mercadoria ser uma fase na vida das coisas e não um tipo de coisa (APPADURAI, 2008; KOPYTOFF, 2008) pode ser observada: os livros, por serem objetos destinados à troca por seus produtores - ou seja, já em seus projetos de origem - são dispostos no mundo como "mercadorias por destinação" (APPADURAI, 2008, p. 30-31). Ao serem encontrados por colecionadores e incorporados às suas coleções, eles são retirados do circuito de troca - do estado/ fase de mercadoria - e passam à fase de ex-mercadorias. A essa condição, soma-se a ressignificação simbólica, que transforma um objeto utilitário por destinação, em semióforo - ponte entre o visível e invisível, objeto carregado de valor simbólico, objeto de coleção (POMIAN, 1984, 1998). No caso da série policial, é com frequência a morte do colecionador que lança esses objetos de volta ao fluxo de mercadorias, sendo este um "acordo oscilante entre rotas socialmente reguladas e desvios competitivamente motivados" (APPADURAI, 2008, p. 31). Em outras palavras, o fim da vida do bibliófilo marca uma nova fase na vida de seus objetos, dando partida nos processos de transmissibilidade das coleções, devolvendo os objetos de coleção ao mundo. Ao retornarem ao circuito mercadológico, tais objetos são dotados de um valor econômico que passa a ser determinado por suas condições de excepcionalidade, ou seja, pela extensão de sua resistência ao desejo que outros têm de possuí-lo (APPADURAI, 2008) - quanto mais difícil de obter, mais valioso é. Tal aspectose encontra representado no quadro: quanto maior e mais complexa a combinação de características excepcionais de um item, maior é o valor de troca anunciado por Janeway.

\section{Considerações finais}

A coleção é um território onde múltiplas esferas da vida humana individual, social, temporal e cultural - convergem. Como campo de construção subjetiva, dentro de uma lógica social que a autoriza/confirma como tal, ela é um espaço de disputas e oscilações, e os objetos que a compõe são os elementos visíveis - pontas de iceberg - desses processos. Apesar da aparente estática pacificada de sua situação - confiantemente quietos em suas estantes -, objetos de coleção são constantemente 
sujeitos a/de dinâmicas, circulando para dentro e para fora das condições de trocabilidade, ascendendo e descendendo na hierarquia das coisas, significando, ressignificando e deixando de significar, para alguém, para em seguida encontrar outro lugar. Em sua trajetória oscilante de valorização/desvalorização - de troca, de uso, de afeto, de produção de conhecimentos - eles nos contam do mundo e dessa coisa igualmente oscilante e dinâmica que eles/neles se espelham/refletem: a experiência humana.

\section{Referências}

ALMEIDA, Marco Antônio de. Literatura, informação, conhecimento e ciência: considerações a partir da literatura policial. In: ALMEIDA, Marco Antônio de. Ciência da Informação e literatura. Campinas, SP: Alínea, 2012. p. 91-118.

APPADURAI, Arjun. A vida social das coisas: as mercadorias sob uma perspectiva cultural. Niterói: EdUFF, 2008.

BAKHTIN, Mikhail. Estética da criação verbal. 6. ed. São Paulo: Martins Fontes, 2011.

BAUDRILLARD, Jean. O Sistema dos objetos. 5. ed. 1. reimpr. São Paulo: Perspectiva, 2012.

BAUMAN, Zygmunt. Entrevista exclusiva. Café filosófico: diálogos com ZygmuntBauman. Leeds, UK: NPEC, 2011. Íntegra da entrevista concedida ao Fronteiras do Pensamento/CPFL, realizada em 23 de julho de 2011. Disponível em:

https://www.youtube.com/watch?v=1miAVUQhdwM. Acesso em: 03 out. 2014.

BENJAMIN, Walter. O colecionador. In: . Passagens. Belo

Horizonte: Editora da UFMG; São Paulo: Imprensa Oficial do Estado de São Paulo, 2006. p. 237-246.

BENJAMIN, Walter. Desempacotando minha biblioteca: um discurso sobre o colecionador. In: . Obras escolhidas II : rua de mão única. 5. ed. São Paulo: Brasiliense, 1995.

CHOAY, Françoise. A alegoria do patrimônio. 4. ed. São Paulo: Estação Liberdade: UNESP, 2011.

CLAUDIO, Ivan. Freud e seus talismãs. Isto é, São Paulo, n. 2129, 27 ago. 2010. Disponível em: http://www. istoe.com.br/reportagens/98241 FREUD+E+SEUS+TALIMAS. Acesso em: 11 nov. 2015. 
COSTA, Robson Santos; ORRICO, Evelyn GoyannesDill. A construção de sentido na informação das histórias em quadrinhos. DataGramaZero, Rio de Janeiro, v. 10, n. 2, abr. 2009. Disponível em:

http://www. datagramazero.org.br/abr09/Art 01.htm. Acesso em: 12 mar. 2014.

COUTINHO, Afrânio. Notas de teoria literária. 2. ed. Rio de Janeiro:

Civilização Brasileira, 1978.

DIAS, Eduardo Wense. O romance policial. In: CAMPELLO, Bernadete Santos; CALDEIRA, Paulo da Terra; MACEDO, Vera Amália Amarante (Orgs.). Formas e expressões do conhecimento: introdução às fontes de informação. Belo Horizonte: Escola de Biblioteconomia da UFMG, 1998. p. 101-113.

DOHMANN, Marcus. A experiência material: a cultura do objeto. Rio de Janeiro: Rio Books, 2013.

DUNNING, John. Edições perigosas. 2. ed. 1. reimpr. São Paulo: Companhia das Letras, 2007.

DUNNING, John. Impressões e provas. São Paulo: Companhia das Letras, 1996.

DUNNING, John. John Dunning's biography. In: DUNNING, John. OldAlgonquin books.[2014]. Disponível em:

http://www.oldalgonquin.com/authorPage.php.Acesso em: 18 jan. 2015.

DUNNING, John. Then and now. In: Booked to die: a mystery introducing Cliff Janeway. Kindle ed. New York: Schreibner, 2000.

DUNIING, John. O último caso da colecionadora de livros. São Paulo: Companhia das Letras, 2009.

ERLL, Astrid. Literature, film and mediataly of cultural memory. In: ERLL, Astrid; NÜNNING, Ansgar (Eds.). A companion to cultural memory studies. Berlim: Nova York: Walter de Gruyter, 2010. p.289-398.

FREITAS, Adriana. Romance policial: origens e experiências contemporâneas. Revista Contracultura, Niterói, n. 01, dez. 2007. Disponível em: http://www.uff.br/revistacontracultura/Adriana\%20Freitas artigo romanc e policial.pdf. Acesso em: 02 ago. 2013.

GORZ, André. O Imaterial: conhecimento, valor e capital. São Paulo: Annablume, 2005. 
JEUDY, Henri-Pierre. O objeto rei. In: . Memórias do social. Rio de Janeiro: Forense Universitária, 1990. p. 64-74. (Coleção, Ensaio \& Teoria).

KOPYTOFF, Igor. A biografia cultural das coisas: a mercantilização como processo. In: APPADURAI, Arjun. A vida social das coisas: as mercadorias sob uma perspectiva cultural. Niterói: EdUFF, 2008. p. 89-121.

LUFT, Celso Pedro. Dicionário prático de regência verbal. 9. ed. 3. reimpr. São Paulo: Editora Ática, 2011.

MARCUSCHI, Luiz Antonio. Gêneros textuais: definição e funcionalidade. In: DIONISIO, Angela Paiva; MACHADO, Anna Rachel; BEZERRA, Maria Auxiliadora (Orgs.). Gêneros textuais e ensino. Rio de Janeiro: Lucerna, 2002.

MARSHALL, Francisco. Epistemologias históricas do colecionismo. Episteme, Porto Alegre, n. 20, p. 13-23, jan./jun. 2005. Disponível em: https://www.researchgate.net/profile/Francisco Marshall/publication/ 264849099 EPISTEMOLOGIAS HISTORICAS DO COLECIONISMO/links/5 42ad07f0cf29bbc126a7565.pdf.Acesso em: 01 out. 2011.

MELO, Kelly Castelo Branco da Silva. Bibliofilia: um tipo de colecionismo, um caminho de coleção e memória. 2011. 47 f. Trabalho de Conclusão de Curso (Graduação em Biblioteconomia)-Escola de Biblioteconomia, Universidade Federal do Estado do Rio de Janeiro, Rio de Janeiro, 2011.

MELO, Kelly Castelo Branco da Silva. Bibliófilos e bibliodetetives: personagens de patrimônio e memória. 2015. 175 f. Dissertação (Mestrado em Memória Social)-Programa de Pós-graduação em Memória Social, Universidade Federal do Estado do Rio de Janeiro, Rio de Janeiro, 2015.

MOLES, Abraham A. Objeto e comunicação. In: MOLES, Abraham A. et al. Semiologia dos objetos. Petrópolis, RJ: Vozes, 1972.

MOLES, Abraham A. Teoria dos objetos. Rio de Janeiro: Tempo Brasileiro, 1981.

MORAES, Rubens Borba de. O bibliófilo aprendiz, ou, Prosa de um velho colecionador para ser lida por quem gosta de livros, mas pode também servir de pequeno guia aos que desejam formar uma coleção de obras raras antigas ou modernas. 4. ed. Rio de Janeiro: Casa da Palavra, 2005.

OLIVEIRA, Andréia Machado; SIEGMANN, Christiane; COELHO, Débora. As coleções como duração: o colecionador coleciona quê? Episteme, Porto Alegre, n. 20, p. 111-119, jan./jun. 2005. Disponível em: 
http://www.ilea.ufrgs.br/episteme/portal/pdf/numero20/episteme20_artig o_oliveira_siegman_coelho.pdf.Acesso em: 01 out. 2011.

PEARCE, Susan M. On collecting: an investigation into collecting in the European tradition. New York: Routledge, 2013.

PEARCE, Susan M.Museums, objects and collections: a cultural study. Washington, D.C.: Smithsonian Institution Press, 1992.

POMIAN, Krzysztof. Colecção. In: Memória-História. Enciclopédia Einaudi, v. 1. Ed. Portuguesa. Lisboa: Imprensa Nacional: Casa da Moeda, 1984. v. 1 , p. $51-86$.

POMIAN, Krzysztof. História cultural, história dos semióforos. In: RIOUX, Jean Pierre; SIRINELLI, Jean-François (Dirs.). Para uma história cultural. Lisboa: Editorial Estampa, 1998.

RIBEIRO, Leila Beatriz. Mais do que posso contar: coleções, imagens e narrativas. In: PROGRAMA DE PÓS GRADUAÇÃO EM MEMÓRIA SOCIAL. Processo seletivo discente: cursos mestrado e doutorado: edital $\mathrm{n}$. 12/2015, 2014. Disponível em:

http://www.memoriasocial.pro.br/pdf/edital.pdf. Acesso em: 28 set. 2014.

RIBEIRO, Leila Beatriz. Manias, trecos, objetos e coleção: memória, descarte e velhice nas narrativas quadrinísticas de Urbano, o aposentado. In: ENCONTRO REGIONAL DA ANPUH-RIO, 19., 2010, Rio de Janeiro. Anais... Rio de Janeiro: NUMEN, 2010. Disponível em: http://www.memoriasocial.pro.br/linhas/professores dados.php?id=19. Acesso em: 06 out. 2011.

TODOROV, Tzvetan. A origem dos gêneros. In: TODOROV, Tzvetan. Os gêneros do discurso. São Paulo: Martins Fontes, 1980. 